\title{
Changes in Asthma Mortality in England and Wales since 2001
}

Dominick E. Shaw ${ }^{1}$, Catherine M. Gaynor ${ }^{2}$, Andrew Fogarty ${ }^{3}$

1. NIHR Respiratory Biomedical Research Centre, University of Nottingham, Nottingham, UK. NG5 1PB

2. Department of Health Care of Older People, Nottingham University Hospitals NHS Trust Nottingham, UK. NG7 2UH

3. Division of Epidemiology and Public Health, University of Nottingham, Nottingham, UK. NG5 1PB

Corresponding author:

Prof Dominick Shaw

Clinical Sciences Building,

Division of Respiratory Medicine,

University of Nottingham,

Nottingham NG5 1PB

Orchid ID 0000-0003-4106-8469

Email: dominic.shaw@nottingham.ac.uk

Phone: 01158231710

Fax: 01158230581

Key words:

Asthma

Asthma Epidemiology

Word Count: 877 


\section{Abstract}

The number of deaths from asthma in England and Wales has not changed significantly over the last decade. This lack of improvement has received attention from both national asthma guidelines and the media. We examined asthma death data from the Office for National Statistics, stratified by age band. Every 5 year age band below the age of 80 years has seen a large reduction in mortality between 2001 and 2017, whereas numbers of asthma deaths have increased by $81 \%$ for people aged 80 or above. This increase in older people dying from asthma requires explanation.

\section{Introduction}

In the UK recent press attention has focussed on how death rates from asthma compare unfavourably to the rest of Europe [1]; according to data from Eurostat the number of asthma deaths in the UK has increased by more than $20 \%$ in five years, with figures from 2015 showing 1434 people dying from an asthma attack. Attention has also fallen on asthma mortality in young people; the UK has the worst mortality rate in people aged 10-24 included, and the second highest among 15- to 19-year-olds in European countries [2].

Conversely a recent paper describes asthma mortality, emergency admissions and prevalence as decreasing over recent decades in England, although mortality did appear to be related to socioeconomic status with a 19\% lower mortality among 5-44 year olds in the most deprived quintile compared to those in the least deprived quintile. In older adults this trend was reversed [3].

\section{Methods}

To investigate this apparent discrepancy and explore the age distribution of asthma deaths in more detail we examined the raw numbers of deaths from asthma across England and Wales in the period 2001-2017 using data from the Office for National Statistics (ONS) which compiles data from death certificates using the International Classification of Diseases Version 10 (ICD-10) codes J45 and J46 for asthma.

Raw data were grouped into 5 year age bands ( $<1$ year, 01-04 years, 05-09 years, 10-14 years etc.) up to $85-89$ and $>90$ years. In order to explore the possibility of miscoding on asthma deaths as a potential issue we also obtained data on 5 year age bands for deaths from COPD (Chronic Obstructive Pulmonary Disease) using ICD-10 codes J40-44. To calculate and plot annual asthma and COPD mortality rates we used 2011 population data as a baseline; 
https://www.ons.gov.uk/peoplepopulationandcommunity/populationandmigration/populatione stimates/datasets/2011censuspopulationandhouseholdestimatesforenglandandwales

(Accessed 17/5/2019). For ease of presentation, data were split into age related quintiles- 024 years, 25-49 years, 50-74 years and $>75$ years.

\section{Results}

There was only a 2.5\% reduction in asthma deaths in England and Wales from 2001 to 2017 (see Table 1). However, when stratified by age there was large variation in the change in number of deaths over time. For those below the age of 75 years there was a $53 \%$ reduction in deaths, as compared to a $50 \%$ increase in deaths from asthma in people aged over 75 years. In the same period there was a $22.4 \%$ increase in deaths from COPD in people over 75 years. The trends for death from asthma and COPD in people stratified by age are seen in Figures 1 and 2.

\section{Conclusion}

There has been no overall change in the numbers of asthma deaths in England and Wales since 2001, however there has been a large drop in deaths in people under the age of 75 , with a corresponding increase in those aged over 75 . There has also been a corresponding rise in the number of people dying from COPD.

The cause of such divergent trends based on age in asthma mortality is unclear. The difference may reflect disease chronicity with airway remodelling and consequent reduced response to bronchodilators in older people. Older people can also be more sensitive to side effects from beta adrenergic agonists and glucocorticoids, especially in the face of polypharmacy, and many have difficulty using inhalers correctly [4]. There is evidence that asthma exacerbation rates are higher in the older age groups [5] and although anecdotally it is recognised that people who develop asthma at an older age may have a worse outcome [6], an older age of onset of asthma does not appear to be associated with higher exacerbation rates [7].

The differential mortality rates after stratification by age may reflect the misattribution of the cause of death as asthma rather than as a different respiratory disease such as COPD; we also collected data on COPD deaths and a similar increase was observed above and the age of 75 years.

The potential issue of miscoding was flagged in the National Review of Asthma Deaths (NRAD) [8], where 514/1414 (36\%) of the deaths in the 12 months from February 2011 with 
asthma in part II of the Medical Certificate Cause of Death (MCCD) were possibly erroneously classified as J459; i.e. deaths due to asthma. Complex rules applied by the World Health Organisation for classifying diseases in order to determine the underlying cause of death based on death certificates can result in considerable variation in the subsequent assignment of the cause of death. However it is still important to note that most of the deaths from asthma examined in NRAD were thought to be preventable.

Whatever the reason for the apparent age difference in mortality more research is needed into this rise in deaths from asthma in the older population. This is particularly pertinent as it is estimated that many elderly patients with asthma are treated with drugs that have not been tested in older populations and that older people with asthma are often excluded from clinical studies because of age based inclusion criteria and co-morbidities; one study found the odds ratio of being excluded from RCTs increased to 18.6 at the age of 75-84 years when compared to the youngest populations [9].

In summary the stable rate of asthma deaths seen over the last 18 years hides significant differences related to age. The apparent increase in deaths from asthma in an older population needs explanation if we are to improve asthma outcomes in the context of an ageing population.

\section{References}

1 Press release | UK asthma death rates among worst in Europe | Asthma UK. Asthma UK. https://www.asthma.org.uk/about/media/news/press-release-uk-asthma-deathrates-among-worst-in-europe/ (accessed 12 Mar 2019).

2 International comparisons of health and wellbeing in adolescence and early adulthood. https://www.nuffieldtrust.org.uk/files/2019-02/1550657729_nt-ayph-adolescent-healthreport-web.pdf

3 Gupta RP, Mukherjee M, Sheikh A, et al. Persistent variations in national asthma mortality, hospital admissions and prevalence by socioeconomic status and region in England. Thorax 2018;73:706-12.

4 Reed CE. Asthma in the elderly: diagnosis and management. J Allergy Clin Immunol 2010;126:681-7; quiz 688-9.

5 Bloom Cl, Saglani S, Feary J, et al. Changing prevalence of current asthma and inhaled corticosteroid treatment in the UK: population based cohort 2006-2016. Eur Respir J Published Online First: 14 February 2019. doi:10.1183/13993003.02130-2018

6 Battaglia S, Benfante A, Spatafora M, et al. Asthma in the elderly: a different disease? Breathe (Sheff) 2016;12:18-28.

7 Mirabelli MC, Beavers SF, Chatterjee AB, et al. Age at asthma onset and subsequent 
asthma outcomes among adults with active asthma. Respir Med 2013;107:1829-36.

8 Levy ML. Why Asthma Still Kills: The National Review of Asthma Deaths (NRAD). Royal College of Physicians of London 2014.

9 Battaglia S, Basile M, Spatafora M, et al. Are asthmatics enrolled in randomized trials representative of real-life outpatients? Respiration 2015;89:383-9.

Table 1

Numbers of death from asthma or COPD in 2001 and 2017 in England and Wales

Asthma Deaths

\begin{tabular}{|l|l|l|l|l|l|l|l|}
\cline { 2 - 8 } $\begin{array}{l}\text { Age Band } \\
\text { (years) }\end{array}$ & 2001 & 2017 & $\%$ change & & 2001 & 2017 & $\%$ change \\
\hline $0-24$ & 48 & 18 & -62.5 & & 8 & 5 & -37.5 \\
\hline $25-49$ & 137 & 51 & -62.8 & & 163 & 181 & +11 \\
\hline $50-74$ & 459 & 234 & -49 & & 8113 & 9063 & +11.7 \\
\hline$>75$ & 620 & 930 & +50 & & 16120 & 19814 & +22.4 \\
\hline Total & 1264 & 1233 & -2.5 & & 24404 & 29063 & +19.1 \\
\hline
\end{tabular}

Figure 1 Asthma Mortality (deaths/1000 population), 2001 to 2017 in England and Wales

Figure 2 COPD Mortality (deaths/1000 population), 2001 to 2017 in England and Wales

\section{Contributorship}

Prof Shaw initiated the project, wrote the manuscript and acts as guarantor.

Dr Gaynor contributed to the manuscript.

Dr Fogarty helped analyse the data and contributed to the manuscript.

Funding

No funders were involved in this submission 


\section{Competing interests}

None to declare

\section{Exclusive license}

I, the Submitting Author has the right to grant and does grant on behalf of all authors of the Work (as defined in the below author licence), an exclusive licence and/or a non-exclusive licence for contributions from authors who are: i) UK Crown employees; ii) where BMJ has agreed a CC-BY licence shall apply, and/or iii) in accordance with the terms applicable for US Federal Government officers or employees acting as part of their official duties; on a worldwide, perpetual, irrevocable, royalty-free basis to BMJ Publishing Group Ltd ("BMJ") its licensees and where the relevant Journal is co-owned by BMJ to the co-owners of the Journal, to publish the Work in Thorax and any other BMJ products and to exploit all rights, as set out in our licence. 